\title{
ANISOTROPY AND SPATIAL VARIATION OF RELATIVE PERMEABILITY AND LITHOLOGIC CHARACTER OF TENSLEEP SANDSTONE RESERVOIRS IN THE BIGHORN AND WIND RIVER BASINS, WYOMING
}

\author{
D.O.E. Contract No. DE-AC22-93BC14897
}

Contract Starting Date: September 15, 1993

Contract Completion Date: September 14, 1996

D. O. E. Award for the Current Year: $\$ 251,061$

Second Quarterly, Second Year, Technical Progress Report

Reporting Period: January 1, 1995 -- March 31, 1995

Thomas L. Dunn

Project Manager \& Principal Investigator

Department of Energy Contracting Officer: Mr. Eric T. Bell

April 13, 1995

Institute for Energy Research

Ronald C. Surdam, Director

Thomas L. Dunn, Associate Director

University of Wyoming

Laramie, Wyoming 


\section{DISCLAIMER}

Portions of this document may be illegible in electronic image products. Images are produced from the best available original document. 


\section{Objectives}

This multidisciplinary study is designed to provide improvements in advanced reservoir characterization techniques. This goal is to be accomplished through: (1) an examination of the spatial variation and anisotropy of relative permeability in the Tensleep Sandstone reservoirs of Wyoming; (2) the placement of that variation and anisotropy into paleogeographic, depositional, and diagenetic frameworks; (3) the development of pore-system imagery techniques for the calculation of relative permeability; and (4) reservoir simulations testing the impact of relative permeability anisotropy and spatial variation on Tensleep Sandstone reservoir enhanced oil recovery.

Concurrent efforts are aimed at understanding the spatial and dynamic alteration in sandstone reservoirs that is caused by rock-fluid interaction during $\mathrm{CO}_{2}$-enhanced oil recovery processes. The work focuses on quantifying the interrelationship of fluid-rock interaction with lithologic characterization in terms of changes in relative permeability, wettability, and pore structure, and with fluid characterization in terms of changes in chemical composition and fluid properties. This work will establish new criteria for the susceptibility of Tensleep Sandstone reservoirs to formation alteration that results in change in relative permeability and in wellbore scale damage. This task will be accomplished by flow experiments using core material; examination of regional trends in water chemistry; examination of local water chemistry trends at field scale; and chemical modeling of both the experimental and reservoir systems in order to scale up the experiments to field scale.

\section{Summary of Progress}

The project is on schedule. We have completed the compilation of 192,000 $\mathrm{ft}$. of digitized porosity and gamma-ray well logs of the Tensleep Formation. This computer-based compilation covers the Bighorn and Wind River basins, and portions of the western Powder River Basin and northernmost Green River Basin. The correlation of internal stratification is underway and will be completed in the next quarter.

The laboratory effort continues on schedule. An addition of a research scientist, during this next quarter to the relative permeability measurement effort will allow these tasks to continue to improve productivity. The image analysis task is underway and staffed by a M.S. geology student, Mr. John 
D.O.E. Contract No. DE-AC22-93BC14897, Relative Permeability Anisotropy, Tensleep Sandstone, WY

Humphreys, and the P.I.

The water chemistry and scale formation task personnel preformed another $\mathrm{CO}_{2}$ injection experiment at the Marathon Technology Center.

Determinations of the important controls were made during this last quarter.

TASK 1.0 - REGIONAL FRAMEWORKS. This research will associate spatial distributions and anisotropy of relative permeability with the depositional subfacies and zones of diagenetic alteration found within the Tensleep Sandstone. The associations between depositional lithofacies, diagenetic alteration, and pore geometry will strongly link relative permeability with the distinct and measurable dimensions of lithofacies and authigenic mineral facies. Effects of the depositional processes and burial diagenesis will be investigated.

During the winter quarter, data acquisition and interpretation continued at a steady pace, and Task 1.0 is on schedule. As of March 31, 96 additional wells with digitized logs have been added to the Production Analyst@ database for both the Bighorn and Wind River basins. This brings the total to approximately 64,000 feet each for GR, Neu, and Den digitized well logs. We have also increased our understanding of the well log response of particular facies and bounding surfaces by describing ten Tensleep Sandstone cores which total approximately 2300 feet, and correlating them to the well log response. These data have made it possible to expand the regional correlations of marine carbonate units across the Bighorn Basin. To improve subsurface data manipulation skills, Dr. Crabaugh attended a class on the use of Production Analyst@ (Oil and Gas Consultants Inc.).

During the next quarter, the first iteration of the regional correlations within and between both basins will be completed. Maps of individual units within the Tensleep will be constructed. Preparations will be made for the summer field work in the mountains surrounding the Wind River Basin. Outcrop description combined with subsurface data will improve the correlations of key units from the Bighorn Basin into the Wind River Basin. 
TASK 2.0 - RELATIVE PERMEABILITY MEASUREMENTS. The focus of this task is to obtain quantitative laboratory data on the magnitude and variability of relative permeability anisotropy and spatial variation of the dominant reservoir and boundary surface lithologies of the Tensleep Sandstone. Existing data will be collected, compiled, and placed within the regional frameworks constructed in Task 1.0. Laboratory measurements will be performed in the Petroleum Engineering Department at the University of Wyoming. Relative permeability will be measured using the unsteady-state technique. An additional objective of this study is to provide algorithms for calculating relative permeability from quantitative pore imagery data.

Relative permeability measurements of Tensleep sandstone cores continue. Samples through letter "I" are now completed for both vertical and horizontal measurements. At this point, Iraj Ajdari is assembling results to date through sample "I", and compiling his M.S. thesis for submittal to the department of Chemical and Petroleum Engineering. His conclusions are as follows:

1. Dried air permeabilities are reasonably isotropic in these sands. A very slight deviation from equality of vertical and horizontal permeabilities exists with the horizontal gas permeability being negligibly larger.

2. When saturated with oil, then waterflooded, the residual oil saturation and percent recovery of oil by waterflooding appears to be a random function. A wide range of residual saturations exists, with no preference toward vertical and horizontal.

3. Relative permeability ratios (water/oil) show a distinct trend in anisotropy. The horizontal relative permeability ratio is regularly smaller, that is it hàs greater permeability for oil.

Reservoir simulation work has been initiated by considering the four 
D.O.E. Contract No. DE-AC22-93BC14897, Relative Permeability Anisotropy, Tensleep Sandstone, WY

computer programs already available at University of Wyoming. These four programs are: Stiles1, Dykstra-Parsons2, TETRAD (TM), and Buckley-Leverett3. Each is operational on IBM compatible PC's and each has been considered for applicability to this relative permeability anisotropy study. The Stiles program will not be used, as it is predominantly designed to handle layers of differing absolute permeability with no account for relative permeability equations. The Dykstra-Parsons program is a two-dimensional stream-tube model, based upon a simplified relative permeability model. Although this appeared attractive at first, the existing program assumes equal relative permeability parameters in all directions. Therefore, Dykstra-Parsons as it exists has no way to handle relative permeability anisotropy accurately The program also is limited to single layer modeling with no vertical cross-flow between layers. TETRAD is currently used by the reservoir simulation class in petroleum engineering at University of Wyoming. It is a general purpose three-dimensional black-oil simulator, streamlined to run on a 486 PC. Unfortunately, the stream lining process has limited the program to 200 finite difference cells, which practically means that a user is limited to two-dimensional problems. Then, the input and output of variables is complexly awkward and slow. A single run of the program, from set-up to compilation of results, can take many man-days. And finally, the license to U.W. is for classroom use only, so would technically have to be upgraded for this project. A simpler, yet still theoretically sound approach is needed.

The Buckley-Leverett program is a simple one-dimensional program that follows accurately the complete relative permeability behavior as predicted by Buckley-Leverett theory. The major disadvantage of this program is the fact that it is one-dimensional. It's advantage is the adaptation to variable relative permeability characteristics of oil/water systems. Each relative permeability curve is input to the Buckley-Leverett program by characterizing the residual end-point saturations, and then behavior between end-points by a power law 
D.O.E. Contract No. DE-AC22-93BC14897， Relative Permeability Anisotropy, Tensleep Sandstone, WY

relationship against dimensionless saturation. As all our results appear to follow power law relationships quite well, the program seems well suited for this project. Sample runs have been completed, and only preliminary results are available. We plan to overcome the one-dimensional limitations by running the program once with horizontal permeability parameters, then again with vertical permeability parameters. Comparison of the two separate runs will allow evaluation of approximate effects from anisotropy in oil and water production during waterflooding. These results can also be compared to previously published waterflooding simulation studies to assess the level of uncertainty imparted by accounting for relative permeability anisotropy.

A slightly similar study was published by Kortekaas4 where reservoir simulation was performed with assumptions of varying water/oil displacement characteristics in cross-bedded reservoirs. In that work, however, the variations were assumed to be derived by scaling the reservoir at two sizes, once to account for the cross-bedding effects at a very fine scale (small grids), and a second time to perform the actual reservoir simulation studies. There were never any actual permeability measurements included in that study. It was primarily a technique for handling small scale (cross-bedding) variations with a large scale (reservoir) simulation program. Many of the assumptions made in that work can now be evaluated quantitatively with the laboratory data we have acquired to date. References:

1. Stiles, W.E.: "Use of Permeability Distributions in Water-flood Calculations," Transactions AIME (1949) 186, 9-13.

2. Dykstra, H., and Parsons, R.L.: "The Prediction of Oil Recovery by Waterflood," Secondary Recovery of Oil in the United States, API, Dallas (1950) 160-74.

3. Buckley, S.E., and Leverett, M.C.: "Mechanism of Fluid Displacement in Sands," Transactions AIME (1942) 146, 107-16.

4. $\quad$ Kortekaas, T.F.M.: "Water/Oil Displacement Characteristics in Crossbedded Reservoir Zones," Society of Petroleum Engineering Journal (Dec. 1985) 917-26. 


\section{TASK 3.0, CO2 FLOOD - FORMATION ALTERATION AND WELLBORE}

DAMAGE. The work of this task is to establish criteria for susceptibility of Tensleep reservoirs to formation alteration resulting in a change in absolute or relative permeability and possible wellbore scale damage during $\mathrm{CO}_{2}$ enhanced oil recovery. This advanced reservoir characterization technology will be used to optimize recovery efficiency. This task includes: (a) flow experiments on core material to examine the effects of $\mathrm{CO}_{2}$ flooding on the alteration of the fluid and rock system; (b) examination of regional trends in water chemistry; (c) examination of local water chemistry trends at field scale; and $(d)$ chemical modeling of both the reservoir and experimental systems in order to scaleup the experiments to reservoir conditions.

We found that Tensleep formation water chemistry can be classified into four groups and that the distribution of waters of each group in the Bighorn Basin is characteristic. We interpret that these features reflect water-rock interaction between Tensleep sandstone minerals and post-Laramide meteoric water, depositional environments of the formation, and hydrogeology in the Bighorn Basin.

We have carried out a computer simulation of carbonate scale formation in the Tensleep formation due to $\mathrm{CO}_{2}$-flooding. We calculated saturation index of aragonite, which is a common scale mineral caused by $\mathrm{CO}_{2}$-flooding, as a function of $\mathrm{PCO}_{\mathrm{CO}}$ due to well-to-well $\mathrm{CO}_{2}$-flooding using SOLMINEQ.88 computer program. Through this simulation, we found that the dissolution rate of dolomite, which is a common cement mineral in the Tensleep, is the most important factor controlling scale formation of aragonite near production wells. More detailed simulation is in progress.

The second run of $\mathrm{CO}_{2}$-flooding experiment was carried out at the Petroleum Technology Center, Marathon Oil Company, Littleton, CO in January 1995. This run was a blank test to assess chemical Fe contamination from the apparatus and was run under the same conditions as those of the first run without cores $\left(80^{\circ} \mathrm{C}\right.$ and $\left.2400 \mathrm{psi}, \mathrm{P}_{\text {total }}=\mathrm{P}_{\mathrm{CO} 2}\right)$. We observed that a fair amount of Fe (max. 515 ppm) came out of the apparatus. We are now rechecking the 
D.O.E. Contract No. DE-AC22-93BC14897, Relative Permeability Anisotropy, Tensleep Sandstone, WY

results of the first run taking into account Fe contamination we measured in this run. From the results of these two runs, we are also trying to estimate the dissolution rate of dolomite under $\mathrm{CO}_{2}$-flooding conditions, because we found that this rate is an important factor controlling aragonite scale formation due to $\mathrm{CO}_{2}$ treatments through the computer simulation. The third experiment will be run in the next quarterly period. The next experiment will run longer than the previous two, and we will focus, in particular on the change of the degree of saturation of dolomite with time.

TASK 4.0 - PROJECT MANAGEMENT AND TECHNICAL TRANSFER. This task incorporates efforts to achieve a high level of success in this interdisciplinary project. This administrative task provides for effective coordination and integration of the project's research tasks. The program manager is responsible for ensuring that the task workers meet on a frequent and regular basis to exchange information and discuss results. The program manager is responsible for the coordination and timely reporting of results to its Industry Advisor/Mentors, the Department of Energy, and the scientific and engineering communities.

Tasks 1.0 and 3.0 findings were presented in oral and poster sessions at the American Association of Petroleum Geologists Annual Convention in Houston in early March. The poster was very well received and well attended. The poster illustrated Tensleep depositional processes and the resultant effect on both largeand small-scale reservoir heterogeneity. Large photomosaics were used to illustrate the four basic reservoir fluid-flow units and their dimensions. The outcrop photos were integrated with subsurface cross-sections to further illustrate the lateral geometries and dimensions of the eolian and marine facies.

The oral presentation on the water chemistry and $\mathrm{CO}_{2}$ injection modeling was also well received. The strong control of the dolomite dissolution rate on carbonate scale formation and hence on predictive modeling of scale formation was presented in this talk given by Dr. Shiraki. 
D.O.E. Contract No. DE-AC22-93BC14897, Relative Permeability Anisotropy, Tensleep Sandstone, WY

A research scientist position was created in order to maintain the Task $2.0^{\circ}$ laboratory effort after Mr. Ajdari graduates this summer. A search for candidates will begin in the next quarter.

\section{DISCLAIMER}

This report was prepared as an account of work sponsored by an agency of the United States Government. Neither the United States Government nor any agency thereof, nor any of their employees, makes any warranty, express or implied, or assumes any legal liability or responsibility for the accuracy, completeness, or usefulness of any information, apparatus, product, or process disclosed, or represents that its use would not infringe privately owned rights. Reference herein to any specific commercial product, process, or service by trade name, trademark, manufacturer, or otherwise does not necessarily constitute or imply its endorsement, recommendation, or favoring by the United States Government or any agency thereof. The views and opinions of authors expressed herein do not necessarily state or reflect those of the United States Government or any agency thereof. 